\title{
A guaranteed cost control of the uncertain discrete-time output PDFs systems with both STSTE and input delays
}

\author{
Wang Xue-Xia \\ Department of Electrionics and Information Engineering \\ Xianyang Vocational Technical College \\ Xianyang,China \\ E-mail:wangxuexiayc@163.com
}

Abstract-In this paper,the guaranteed cost control problem for uncertain discrete-time output probability density functions(PDFs) with both state and input delay is investigated .A novel linear matrix inquality (LMI)-based approach with model transformation is developed,so that the closed-loop system is asyptotially stable and a given performance index is not more than a specified upper bound for all admissible uncertainties,furthermore ,to ensure that

\section{INTRODUCTION}

Probability density function (PDF) control aim to control the shape of the system output probability density functions to track the shape of the given probability density function for non-Gaussian and dynamic stochastic systems([1-8]). different form both the traditional stochastic control and the PDF control, the PDF control aims at making the statistical information of the system output PDFs follow those of a target(given) PDF for non-Gaussian systems.

In the past several decades, Lei Guo and Hong et al.,have contributed much to the development of the output PDFs control ,and Many effective methods have also been developed. But all of the methods were designed by using numerical solutions.This led to control algorithms with a high computational load and cannot be guaranteed to be stable for the output PDF systems.In the paper,it is desirable to design a controller which is not only stable but also guarantees an adequate level of performance for uncertain discrete-time PDFs systems with state-and-input delays.

\section{PROBLEM STATEMENT}

The purpose of the guaranteed cost methods is to choose control input $\left\{\mathrm{u}_{\mathrm{i}}(\mathrm{t})\right\}$ as close as possible to a prespecified
Shi Jing

Department of Electrionics and Information Engineering Xianyang Vocational Technical College

Xianyang,China

E-mail: 258587000@qq.com

the system output probability density function is made as close as possible to the given probability density function. A comparative study of an example problem has show that the proposed method can guarantee the good performance index,tracking and robustness.

Keywords- Probability density fuctions; Guaranteed cost control;Linear matrix inquality

probability density function $\gamma_{\mathrm{g}}(\mathrm{y})([1,2])$, such that the actual probability density functions of the system output is made, which is defined on $[a, b]$ and is independent of $\left\{\mathrm{u}_{\mathrm{i}}(\mathrm{t})\right\}$, so as to guarantees not only robust stability but also an adequate level of performance index as well for uncertain the PDF systems with both input and state delays. this is equivalent to choosing $\{\mathrm{u}(\mathrm{t})\}$ such that $\sqrt{\gamma(\mathrm{y}, \mathrm{u}(\mathrm{t})}$ is made as close as possible to $\sqrt{\gamma_{\mathrm{g}}(\mathrm{y})}$.

For the above purpose,the following new state vector and a some new matrix are defined

$$
\sqrt{\gamma(\mathrm{y}, \mathrm{u}(\mathrm{k}))}=\widetilde{\mathrm{B}}(\mathrm{y}) \widetilde{\mathrm{V}}(\mathrm{k})
$$

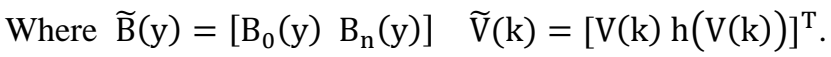

The prespecified probability density function $\gamma \mathrm{g}(\mathrm{y})$ can be expressed in terms of B-spline basis functions to obtain

$$
\sqrt{\gamma_{g}}=\sqrt{\left(B_{0}(y) V_{g}+h\left(V_{g}\right) B_{n}\right)}=\widetilde{B}(y) \widetilde{V}_{g}
$$

Where $\widetilde{V}_{g}=\left[\begin{array}{ll}V_{g} & h\left(V_{g}\right)\end{array}\right]^{T}$.

For the guaranteed cost control of the output PDF,the following performance function that contains a measure of distance between the output PDF and the target PDF is given 


$$
\begin{aligned}
& \mathrm{J}=\sum_{\mathrm{k}=0}^{\infty}\left[\left(\sqrt{\gamma(\mathrm{y}, \mathrm{u}(\mathrm{k}))}-\sqrt{\gamma_{\mathrm{g}}}\right)^{\mathrm{T}}\left(\sqrt{\gamma(\mathrm{y}, \mathrm{u}(\mathrm{k})}-\sqrt{\gamma_{\mathrm{g}}}\right)\right. \\
& \left.+\mathrm{u}^{\mathrm{T}}(\mathrm{k}) \mathrm{Ru}(\mathrm{k})\right]=\sum_{\mathrm{k}=0}^{\infty}\left[\mathrm{X}^{\mathrm{T}}(\mathrm{k}) \mathrm{QX}(\mathrm{k})+\mathrm{u}^{\mathrm{T}}(\mathrm{k}) \mathrm{Ru}(\mathrm{k})\right]
\end{aligned}
$$

Where $\quad \mathrm{x}(\mathrm{k})=\widetilde{\mathrm{V}}(\mathrm{k})-\widetilde{\mathrm{V}}_{\mathrm{g}}, \mathrm{Q}=\widetilde{\mathrm{B}}^{\mathrm{T}}(\mathrm{y}) \widetilde{\mathrm{B}}(\mathrm{y})=\|\widetilde{\mathrm{B}}(\mathrm{y})\|^{2}$, $\mathrm{Q}>0, \mathrm{R}>0$ is prespecified weighting matrices that impose an energy constraint for control. In this paper,equation (3) is condidered as guaranteed cost function for uncertain discrete-time the PDF system with both input and state delays.

In this paper, let us assumed that that the following state space form

$$
\begin{gathered}
\mathrm{x}(\mathrm{k}+1)=(\mathrm{A}+\Delta \mathrm{A}) \mathrm{x}(\mathrm{k})+\left(\mathrm{A}_{\mathrm{d}}+\Delta \mathrm{A}_{\mathrm{d}}\right) \mathrm{x}(\mathrm{k}-\mathrm{d}) \\
+(\mathrm{B}+\Delta \mathrm{B}) \mathrm{u}(\mathrm{k}) \\
+\left(\mathrm{B}_{\mathrm{h}}+\Delta \mathrm{B}_{\mathrm{h}}\right) \mathrm{u}(\mathrm{k}-\mathrm{h}) \\
\sqrt{\gamma(\mathrm{y}, \mathrm{u}(\mathrm{k}))}=\widetilde{\mathrm{B}}(\mathrm{y}) \widetilde{\mathrm{V}}(\mathrm{k})=\widetilde{\mathrm{B}}(\mathrm{y})\left(\mathrm{V}_{\mathrm{g}}+\mathrm{x}(\mathrm{k})\right)
\end{gathered}
$$

Can be used to represent the dynamic relationship between measured state vector $\mathrm{x}(\mathrm{k}) \in \mathrm{R}^{\mathrm{n}}$ and control input vector $\mathrm{u}(\mathrm{k}) \in \mathrm{R}^{\mathrm{m}}$. A, Ad, $\mathrm{B}$, and $\mathrm{Bd}$ are known real constant matrices of appropriate dimensions, $\Delta \mathrm{A}, \Delta \mathrm{Ad}, \Delta \mathrm{B}$, and $\Delta \mathrm{Bd}$ denote real time-varying matrices matrices representing parameter uncertainties, $\mathrm{d}$ and $\mathrm{h}$ represent unknown time-delay integers in the state and control input. In general, Note that $0 \leq \mathrm{d} \leq$ $\mathrm{d}^{*}, 0 \leq \mathrm{h} \leq \mathrm{h}^{*}$ with $\mathrm{d}^{*}$ and $\mathrm{h}^{*}$ being known upper bounds of the state-and-input delay.

The system uncertainties being norm-bound can be further expressed as

$$
\left[\begin{array}{cc}
\Delta \mathrm{A} & \Delta \mathrm{A}_{\mathrm{d}} \\
\Delta \mathrm{B} & \Delta \mathrm{B}_{\mathrm{h}}
\end{array}\right]=\mathrm{DF}\left[\begin{array}{cc}
\mathrm{E}_{\mathrm{a}} & \mathrm{E}_{\mathrm{b}} \\
\mathrm{E}_{\mathrm{d}} & \mathrm{E}_{\mathrm{h}}
\end{array}\right]
$$

Where $F \in R^{i \times j}$ is an unknown marix satisfying $F^{T} F \leq I$, $\mathrm{Ea}, \mathrm{Eb}, \mathrm{Ed}, \mathrm{Eh}$ and $\mathrm{D}$ are known constant matrices.

Suppose the system state is measurable for feedback, the purpose of guaranteed cost cotroller design is develop to design a robust state feedback control law

$$
\mathrm{u}(\mathrm{k})=\mathrm{Kx}(\mathrm{k})
$$

such that the closed-loop system

$$
x(k+1)=A_{1} x(k)+A_{2} x(k-d)+B_{1} K x(k-h)
$$

is asymptotically stable and the closed-loop value of the guaranteed cost function(15) satisfies

$\mathrm{J} \leq \mathrm{J}^{*}$, which $\mathrm{J}^{*}$ is specified constant. Where

$$
\begin{aligned}
& \mathrm{A}_{1}=\mathrm{A}+\mathrm{KB}+\Delta \mathrm{A}+\mathrm{K} \Delta \mathrm{B} \\
& \mathrm{A}_{2}=\mathrm{A}_{\mathrm{d}}+\Delta \mathrm{A}_{\mathrm{d}} \quad \mathrm{B}_{1}=\mathrm{B}_{\mathrm{h}}+\Delta \mathrm{B}_{\mathrm{h}}
\end{aligned}
$$

equation (8) can be further expressed as

$$
-x(k+1)+A_{1} x(k)+A_{2} x(k-d)+B_{1} K x(k-h)=0
$$

\section{DESIGN OF GUARANTEED COST CONTROLLER}

First,let us introduce a definition

Definition 1. For the stochastic distribution system (4) and guaranteed cost function (3),if there exist a state feedback control law $\mathrm{u}^{*}(\mathrm{k})$ and a positive scalar $\mathrm{J}^{*}$ such that for all $\mathrm{F}$ satisfying $\mathrm{F}^{\mathrm{T}} \mathrm{F} \leq \mathrm{I}$, the closed-loop system(8) is asymptotically stable and the value of the guaranteed cost function (3) satisfied $\mathrm{J} \leq \mathrm{J}^{*}$, then $\mathrm{J}^{*}$ is said to be a guaranteed cost and $\mathrm{u}^{*}(\mathrm{k})$ is said to be a guaranteed cost control law of the PDFs system (4) and gauaranteed cost function (3).

Note that the model transformation of system can obtain a less convervative result. This new method can reduce the convervatism inherent in the robust performance analysis of the PDFs system $(4)([5,6,8,9])$. We now give main results.

Theorem 1. let there exist symmetric positive-definite matrices P,S,T and $\mathrm{N}_{1}, \mathrm{~N}_{2}, \mathrm{~N}_{3}, \mathrm{~N}_{4}$ such that the following matrix inquality hold:

$$
\begin{gathered}
\Pi=\left[\begin{array}{cc}
P+P^{T}+N_{1}^{T} P N_{1} & -P A_{1}+N_{1}^{T} P N_{2} \\
* & \Xi \\
* & * \\
* & * \\
-P A_{2}+N_{1}^{T} P N_{3} & -P B_{1}+N_{1}^{T} P N_{4} \\
A_{1}^{T} P A_{2}+N_{2}^{T} P N_{3} & A_{1}^{T} P B_{1}+N_{2}^{T} P N_{4} \\
A_{2}^{T} P A_{2}+N_{3}^{T} P N_{3}-S & A_{2}^{T} P B_{1}+N_{3}^{T} P N_{4} \\
* & B_{2}^{T} P B_{1}+N_{4}^{T} P N_{4}-T
\end{array}\right]
\end{gathered}
$$

* presents an indicator of terms that are induced by symmetry.

Where $\quad \Xi=\mathrm{S}+\mathrm{Q}-\mathrm{P}+\mathrm{K}^{\mathrm{T}} \mathrm{TK}+\mathrm{K}^{\mathrm{T}} \mathrm{RK}+\mathrm{N}_{2}^{\mathrm{T}} \mathrm{PN}_{2}+$ $\mathrm{A}_{2}^{\mathrm{T}} \mathrm{PA}_{2}$.Then ,for any admissible uncertain matrix $\mathrm{F}$, $\mathrm{u}(\mathrm{k})=\mathrm{Kx}(\mathrm{k})$, is a guaranteed cost controller.

Proof. Let us assume that there exits symmetric positive-definite matrices $\mathrm{P}, \mathrm{S}, \mathrm{T}$ and $\mathrm{N}_{1}, \mathrm{~N}_{2}, \mathrm{~N}_{3}, \mathrm{~N}_{4}$ such that matrix inqulity holds. And then the Lyapunov function

$$
\begin{aligned}
V(k)= & x^{T}(k) P x(k)+\sum_{i=1}^{d} x^{T}(k-i) S x(k-i) \\
& +\sum_{i=1}^{h} x^{T}(k-i) \mathrm{K}^{\mathrm{T}} \mathrm{TK} S x(k-i)
\end{aligned}
$$

is positive-definite. The corresponding Lyapunov fifference along any trajectory of the closed-loop system (4) is obtained as following 


$$
\begin{aligned}
& \Delta V(k)=V(k+1)-V(k)=x^{T}(k+1) \operatorname{Px}(k+1) \\
& +x^{T}(k)\left(S+K^{T} T K-P\right) x(k) \\
& \quad-x^{T}(k-d) S x(k-d)-x^{T}(k-h) K^{T} T K S x(k-h) \\
& +2\left[x(k+1) N_{1}+x(k) N_{2}+x(k-d) N_{3}\right. \\
& \left.+K u(k-h) N_{4}\right] P\left[-x(k+1)+A_{1} x(k)\right. \\
& \left.+A_{2} x(k-d)+B_{1} K x(k-h)\right]
\end{aligned}
$$

Difining vector

$$
\omega=\left[\begin{array}{c}
x(k+1) \\
x(k) \\
x(k-d) \\
K x(k-h)
\end{array}\right]
$$

equation (13) can be further updated as follow

$$
\begin{aligned}
& \Delta V(\mathrm{k})=\omega^{T}\left\{\left[\begin{array}{llll}
P & & & \\
& S+K^{T} T K-P & & \\
& & -S & \\
& & & -T
\end{array}\right]\right. \\
& +\left[\begin{array}{cccc}
N_{1}^{T} P N_{1} & N_{1}^{T} P N_{2} & N_{1}^{T} P N_{3} & N_{1}^{T} P N_{4} \\
* & N_{2}^{T} P N_{2} & N_{2}^{T} P N_{3} & N_{2}^{T} P N_{4} \\
* & * & N_{3}^{T} P N_{3} & N_{3}^{T} P N_{4} \\
* & * & * & N_{4}^{T} P N_{4}
\end{array}\right] \\
& \left.+\left[\begin{array}{cccc}
P & -P A_{1} & -P A_{2} & -P B_{1} \\
* & A_{1}^{T} P A_{1} & A_{1}^{T} P A_{2} & A_{1}^{T} P B_{1} \\
* & * & A_{2}^{T} P A_{2} & A_{2}^{T} P B_{1} \\
* & * & * & B_{1}^{T} P B_{1}
\end{array}\right]\right\} \omega \\
& =\omega^{T}\left[\begin{array}{cc}
P+P^{T}+N_{1}^{T} P N & -P A_{1}+N_{1}^{T} P N_{2} \\
* & \Xi-Q-K^{T} R K \\
* & * \\
* & *
\end{array}\right. \\
& -P A_{2}+N_{1}^{T} P N_{3} \quad-P B_{1}+N_{1}^{T} P N_{4} \\
& A_{1}^{T} P A_{2}+N_{2}^{T} P N_{3} \quad A_{1}^{T} P B_{1}+N_{2}^{T} P N_{4} \\
& A_{2}^{T} P A_{2}+N_{3}^{T} P N_{3}-S \quad A_{2}^{T} P B_{1}+N_{3}^{T} P N_{4} \\
& B_{1}^{T} P B_{1}+N_{4}^{T} P N_{4}-T
\end{aligned}
$$

Under condition(11),we can obtain

$$
\begin{aligned}
\Delta V(\mathrm{k}) & \leq-x^{T}(k)\left(Q+K^{T} R K\right) x(k) \\
& \leq-\lambda_{\text {min }}\left(Q+K^{T} R K\right)\|x(k)\|^{2}
\end{aligned}
$$

Where $\lambda_{\min }($.$) denotes the minimum eigenvalue of matrix$ (.). From Lyapunov stability theary,we conclude that the PDF systems (4) are asymptotically stable.

Then ,Equation (14) can be further expressed as

$$
-\Delta V(\mathrm{k}) \geq x^{T}(k)\left(Q+K^{T} R K\right) x(k)
$$

Summing both side of inequation (15) from 0 to $\infty$,we can obtain

$$
\begin{aligned}
J \leq x^{T}(0) & P x(0)+\sum_{i=1}^{d} x T(-i) S x(-i) \\
& +\sum_{j=1}^{h} x^{T}(-j) K^{T} T K x(-j)
\end{aligned}
$$

We can conclude that the result of the theorem is true from deofinition 1.This completes the proof.

It is noted that the upper bound of the guaranteed cost function depends on the initial condition. In this paper, we apply approach adopted in[4,5] to remove this dependence. Suppose that the initial state of the stochastic distribution system (4) is arbitrary,but belongs to the set

$$
\Phi=\left\{x(-i) \in R^{\mathrm{n}} \mid \mathrm{x}(-\mathrm{i})=\Psi \theta_{\mathrm{i}}, \theta_{\mathrm{i}}^{\mathrm{T}} \theta_{\mathrm{i}} \leq 1, \mathrm{i}=1,2, \cdots, \overline{\mathrm{d}}\right\}
$$

Where $\Psi$ is a given matrix and $\overline{\mathrm{d}}=\max \left\{\mathrm{d}^{*}, \mathrm{~h}^{*}\right\}$, the cost bound (16) then lead to

$$
\begin{aligned}
J \leq & \lambda_{\max }\left(\Psi^{T} P \Psi\right)+d \lambda_{\max }\left(\Psi^{T} S \Psi\right) \\
& +h \lambda_{\max }\left(\Psi^{T} K^{T} P K \Psi\right) \\
\leq & \lambda_{\max }\left(\Psi^{T} P \Psi\right)+d * \lambda_{\max }\left(\Psi^{T} S \Psi\right) \\
& +h^{*} \lambda_{\max }\left(\Psi^{T} K^{T} P K \Psi\right)
\end{aligned}
$$

In the following,we denote that the above sufficient condition of a memoryless state feedback control law which is equivalent to the feasibility of LMI.

Theorem 2. There exist symmetric positive-definite matrices P,S,T such that matrices (11) holds for all admissile uncertainties if and only if there exist $\varepsilon, \rho_{2}, \rho_{3}, \rho_{4}$ and positive-definite matrices $\mathrm{W}, \mathrm{X}, \mathrm{M}, \mathrm{V}$ and $\mathrm{N}$ such that the following LMI(17) holds:

Furthermore, the state feedback control law: $\mathrm{u}(\mathrm{k})=$ $\Sigma \Gamma^{-1} \mathrm{X}(\mathrm{k})$ is a guaranteed cost control law, and the corresponding value of the guaranteed cost fuction satisfies

$$
J \leq\left(1+h^{*}\right) \lambda_{\max }\left(\Psi^{T} \Gamma^{-1} \Psi\right)+d^{*} \lambda_{\max }\left(\Psi^{T} M^{-1} \Psi\right)
$$




$$
\left[\begin{array}{ccccccccccc}
-\Gamma & 0 & -I & A \Gamma+B \Sigma & A_{d} M & B_{h} V & 0 & 0 & 0 & 0 & 0 \\
* & -\Gamma & N & \rho_{2} N \Gamma & \rho_{3} N M & \rho_{4} N V & 0 & 0 & 0 & 0 & 0 \\
* & * & 2 \Gamma+\varepsilon D D^{T} & 0 & 0 & 0 & 0 & 0 & 0 & 0 & 0 \\
* & * & * & -\Gamma & 0 & 0 & \left(E_{a} \Gamma+E_{d} \Sigma\right)^{\mathrm{T}} & \Gamma^{T} & \Sigma^{T} & \Gamma^{T} & \Sigma^{T} \\
* & * & * & * & -M & 0 & M E_{b} & 0 & 0 & 0 & 0 \\
* & * & * & * & * & -V & N E_{h} & 0 & 0 & 0 & 0 \\
* & * & * & * & * & * & -\varepsilon^{-1} I & 0 & 0 & 0 & 0 \\
* & * & * & * & * & * & * & -M & 0 & 0 & 0 \\
* & * & * & * & * & * & * & * & -V & 0 & 0 \\
* & * & * & * & * & * & * & * & * & -Q^{-1} & 0 \\
* & * & * & * & * & * & * & * & * & * & -R^{-1}
\end{array}\right]<0
$$

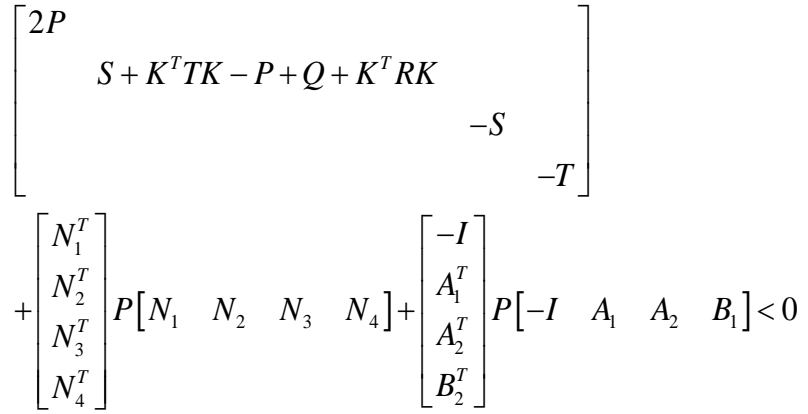

the above inequality can be further lead to

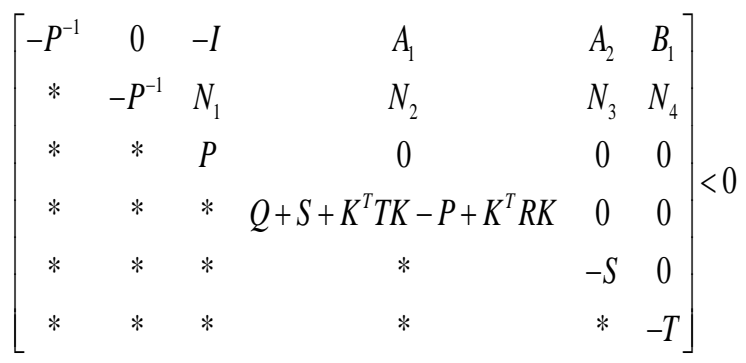

By substitution the representation of matrices $A_{1}, A_{2}, B_{1}$ in the above inequality, it is equivalent to
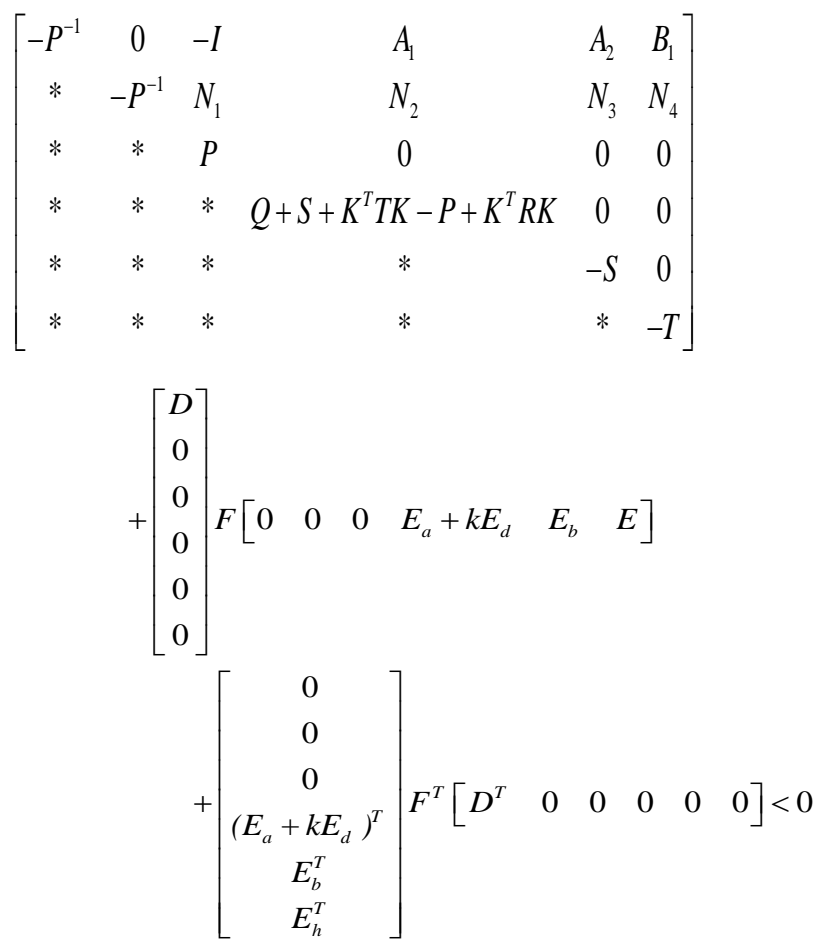

We can get easily

$$
\left[\begin{array}{cccc}
-p^{-1} & 0 & -I & A+K B \\
* & -p^{-1} & N_{1} & N_{1} \\
* & * & 2 P+\varepsilon D D T & 0 \\
* & * & * & S+K^{T} T K-P+Q+K^{T} R K \\
* & * & * & * \\
* & * & * & * \\
* & * & * & *
\end{array}\right.
$$$$
\left.\begin{array}{ccc}
A_{d} & B_{h} & 0 \\
N_{3} & N_{4} & 0 \\
0 & 0 & 0 \\
0 & 0 & E_{a}+k E_{d} \\
-S & 0 & E_{d} \\
* & -T & E_{h} \\
* & * & -\varepsilon^{-1} I
\end{array}\right]<0
$$

By pre-multilying by $\operatorname{diag}\left\{\begin{array}{lllllll}\mathrm{I} & \mathrm{I} & \mathrm{I} & \mathrm{P}-1 & \mathrm{~S}-1 & \mathrm{~T}-1 & \mathrm{I}\}\end{array}\right.$ and post-multiplying $\operatorname{diag}\left\{\begin{array}{lllllll}\mathrm{I} & \mathrm{I} & \mathrm{I} & \mathrm{P}-1 & \mathrm{~S}-1 & \mathrm{~T}-1 & \mathrm{I}\}\end{array}\right.$ both side of LMI (19). At the same time, letting $\Gamma=\mathrm{P}^{-1}, \Sigma=$ $\mathrm{KP}^{-1}, \mathrm{M}=\mathrm{S}^{-1}, \mathrm{~V}=\mathrm{T}^{-1}, \mathrm{~N}_{1}=\mathrm{N}, \mathrm{N}_{2}=\rho_{2} \mathrm{~N}, \mathrm{~N}_{3}=\rho_{3} \mathrm{~N}, \mathrm{~N}_{4}=$ $\rho_{4} N$. And applying Schar lemma yield matrix inequality (18).

If the LMI (17) has a feasible $\varepsilon, \rho_{\mathrm{i}}(\mathrm{i}=$ $1,2,3), \Gamma, \Sigma, \mathrm{V}, \mathrm{M}$, we can obtain that

$$
\mathrm{u}(\mathrm{k})=\Sigma \Gamma^{-1} \mathrm{x}(\mathrm{k})
$$

is a guaranteed cost control law for the system(4) and guaranteed cost function (3).

Furthermore,the corresponding closed-loop cost function satisfies

$$
\begin{aligned}
\mathrm{J} \leq \lambda_{\max }\left(\Psi^{\mathrm{T}} \Gamma^{-1} \Psi\right)+\mathrm{d}^{*} \lambda_{\max }\left(\Psi^{\mathrm{T}} \mathrm{M}^{-1} \Psi\right) \\
+\mathrm{h}^{*} \lambda_{\max }\left(\Psi^{\mathrm{T}} \Gamma^{-1} \Sigma^{\mathrm{T}} \mathrm{V} \Sigma \Gamma^{-1} \Psi\right)
\end{aligned}
$$

From the LMI (17), we have

$$
\left[\begin{array}{cc}
-\Gamma & \Sigma^{\mathrm{T}} \\
\Sigma & -\mathrm{V}
\end{array}\right]<0
$$

Which is equivalent to $\Sigma^{\mathrm{T}} \mathrm{V} \Sigma<\Gamma$, then inequation (18) be obtained. the proof of the theorem 2 is over.

\section{CONCLUSIONS}

In this paper,because numerical solutions cannot be guaranteed to be stable for the output PDFs systems both state 
and input delays, we develop the PDF guaranteed cost state feedback control law with model transformation.the existence condition for the given control law has been derived,and it has been show that this condition is equivalent to the feasibility of a certain LMI. Furthermore,based on the above result,a convex optimization algorithns has been given to optimize gauaranteed cost control law with model transformation. A comparative study of an example problem has show that the proposed method can guarantee the good performance index,tracking and robustness.

\section{REFERENCES}

[1] Guo L,Wang H.:Fault detection and diagnosis for general stochastic systems using B-spline expansions and nonlinear filters. IEEE Trans Circuits Syst I.2005; 52(8): 1644-52.

[2] Guo L,Wang H. Entropy optimization filtering for fault isolation of non-Gaussian systems. In Proc of 6th IFAC symposium on fault detection, super-vision and safety of technical processes. 2006; 432-7.
[3] Guo L,Wang H,Wang.:Optimal probability density function control for NARMAX stochastic systems. Automatica. 2008; 44: 1904-11

[4] Wang H,Wang AP,Wang Y.:An online estimation algorithm for the unknown probability density functions of random parameters in stochastic ARMAX systems. IEE Control Theory Applic D. 2006; 153 : 462-8.

[5] Guo L,Wang H.:Applying constrained nonlinear generalized PI strategy to PDF tracking control through square root B-spline models. Int $\mathrm{J}$ Control.2004; 77(17): 1481-92.

[6] Guo L,Wang H.:PID controller design for output PDFs of stochastic systems using linear matrix inequalities. IEEE Trans Syst, Man Cybern B 2005; 35(1):65-71.

[7] Yi Y, Shen H, Guo L.: Statistic PID tracking control for non-Gaussian stochas-tic systems based on T-S fuzzy model. Int J Automation Comput. 2009; 6(1):81-7

[8] Guo L,Wang H.:Stochastic Distribution Control System Design. Springer, London, 2010.

[9] Hong Wang. Applying observer based FDI techniques to detect faults in dy namic and bounded stochastic distributions. Int J Control. 2000; 73(15):1 424-36.

[10]R. Isermann,P. Balle.Trends in the application of model based fault detection and diagnosis of technical process.in Proc. 13th World Congr. Int. Federation Automatic Control (IFAC'96), San Francisco,CA, 1996, $\mathrm{N}: 1-12$. 